\title{
Large-Scale Analysis of Art Proportions
}

\author{
Jensen, Karl Kristoffer
}

Published in:

Arts and Technology

DOI (link to publication from Publisher):

10.1007/978-3-319-18836-2_16

Creative Commons License

Other

Publication date:

2015

\section{Document Version}

Early version, also known as pre-print

Link to publication from Aalborg University

Citation for published version (APA):

Jensen, K. K. (2015). Large-Scale Analysis of Art Proportions. In A. L. Brooks, E. Ayiter, \& O. Yazicigil (Eds.), Arts and Technology: Fourth International Conference, ArtsIT 2014, Istanbul, Turkey, November 10-12, 2014 , Revised Selected Papers (pp. 137-143). Springer. Lecture Notes of the Institute for Computer Sciences, Social Informatics and Telecommunications Engineering Vol. 145 https://doi.org/10.1007/978-3-319-18836-2_16

\section{General rights}

Copyright and moral rights for the publications made accessible in the public portal are retained by the authors and/or other copyright owners and it is a condition of accessing publications that users recognise and abide by the legal requirements associated with these rights.

- Users may download and print one copy of any publication from the public portal for the purpose of private study or research.

- You may not further distribute the material or use it for any profit-making activity or commercial gain

- You may freely distribute the URL identifying the publication in the public portal -

\section{Take down policy}

If you believe that this document breaches copyright please contact us at vbn@aub.aau.dk providing details, and we will remove access to the work immediately and investigate your claim. 


\title{
Large-Scale Analysis of Art Proportions
}

\author{
Kristoffer Jensen ${ }^{(\varpi)}$ \\ Department of Architecture, Design \& Media Technology (ad:mt), \\ Aalborg University Esbjerg, Niels Bohrsvej 8, 6700 Esbjerg, Denmark \\ krist@create.aau.dk
}

\begin{abstract}
While literature often tries to impute mathematical constants into art, this large-scale study (11 databases of paintings and photos, around 200.000 items) shows a different truth. The analysis, consisting of the width/height proportions, shows a value of rarely if ever one (square) and with majority of images having a proportion larger than one, but less than e.g. the golden ratio. Furthermore, more images have the inversed proportion, meaning that portrait paintings are more common than landscape paintings. The inverse is true for photographs, i.e. more landscape than portrait format photographs has been found in the databases.
\end{abstract}

Keywords: Art $\cdot$ Proportions $\cdot$ Preference $\cdot$ Golden ratio

\section{Introduction}

While math has been used as a model for aesthetics for a long time, few studies have corroborated such model with large-scale empirical findings. Indeed, it is easy to find art examples that match e.g. the golden ratio, but such an example does not in itself constitute proof of the concept (Gardner 1952), and many claims about golden ratios found in art has also been refuted (Markowsky 1992). Still, art is being made with proportions of which many found some more beautiful than others. Many art books will for instance give instructions for painting proportions to be rectangular, but not too much so (sometimes even referring to the golden ratio). Paintings and photos (2D shapes) would exist in rectangular shapes that are higher than wide (portraits) or wider than they are high (landscape). Because of the well-known Shepard table illusion that states than a rectangular shape seen higher than wide as larger compared to if seen wider than large, it could be hypothesized that painting and photos would have less high portraits in order for portraits and landscapes to seem equal. The Shepard table illusion is linked to the horizontal-vertical illusion that states a vertical lines looks longer when presented with a horizontal line, compared to when it is presented alone.

Much art-work has been digitalized in the last years. This digitalization has choices with regards to cropping, colors, etc. In particular, the cropping could potentially have influence on analysis of paintings proportions. Painting are cropped without the frame, and it is in the following assumed that cropping include the entire picture. The largescale of the current experiment is made possible by the digitalization of many art 
collections. In Sect. 2, the supposed links between art and mathematics are reviewed. Section 3 presents the experiment and Sect. 4 offers a conclusion.

\section{Art and Math}

The golden ratio is a mathematical pearl that is found through many methods, of which the most known are the line division (in a line of length $\mathrm{c}$, divided into two sections of length $\mathrm{a}$ and $\mathrm{b}$, when $(\mathrm{a}+\mathrm{b}) / \mathrm{a}=\mathrm{a} / \mathrm{b}$, then the result is the golden ratio $\boldsymbol{\varphi})$, and the division of following Fibonacci (Posamentier and Lehmann 2007) numbers (the limit of Fn/Fn-1 when $\mathrm{n}$ goes to infinity is $\boldsymbol{\varphi})$. The value of the golden ratio $\boldsymbol{\varphi} \approx 1.61$. It has the property that $\boldsymbol{\varphi}-1=1 / \boldsymbol{\varphi}$. Solving this gives the exact value $\boldsymbol{\varphi}=(1+\sqrt{ } 5) / 2$. It is an irrational number. Too many works has tried to find links between the golden ratio and art works (Gardner 1952). Some studies have investigated the aesthetics of this ratio. Green (1995) gives a review of this work, and offers the conclusion that if there is a preference for the golden ratio, it is fragile. Many studies don't provide raw data, not quantitative analysis. Plug (1980), states in the conclusion "there is a broad range of maximum preference for $\mathrm{L} / \mathrm{B}$ ratios in the vicinity of the golden section".

The precision of many studies may also be lacking. If there is a preference, perhaps it is almost equal to the golden ratio. Some older studies, (Fechner et al. 1876 and Lalo 1908), as referred to in Elam (2001, pp. 6-7) has investigated the height/width ratio in common objects and found a preference for proportions in the vicinity of the golden ratio. The preference (found through analysis of books and other objects proportions) was highest for $5 / 8=0.625$, as compared to $2 / 3 \approx 0.67$ and $13 / 23 \approx 0.56$. For more discussions on the validity of the golden section, Boselie (2004) offers a good overview of relevant literature. Some of the propositions to explain the golden ratio, as cited in Boselie (Boselie 2004) are that it corresponds to the visual field, that it corresponds to the proportions of the female face, and many more. Boselie also performed an experiment in which subjects were asked to state their preferences for a shape with golden section and one without. No preference for the golden section was found.

Many paper systems exist, of which the ISO paper size system (Kuhn 2014) is perhaps the most used. In this system, each larger size has width equal to previous height and height equal to double of the previous width. This gives a height/width proportion equal to $\sqrt{ } 2 \approx 1.41$. This ratio enables the same proportions be retained when cutting the paper in two. The ISO paper size system is used in most of the world, except USA. The American letter size has proportions $17 / 11 \approx 1.545$ (letter) and $22 / 17 \approx 1.294$ (legal). Other medias, such as photo cameras has aspect ratios of $4 / 3,3 / 2$ and 16/9, or $5 / 3,5 / 4$, and $1 / 1$ in medium and large formats. TV format has gone from $4 / 3$ to $16 / 9$ in the last few years.

\section{Experiment}

This study main purpose is to assess the empirical preference for width/height proportions. This is done by assuming that this preference is the ruling base for the decision of proportions in painting and photographs. A large database of digitalized painting and 
photos has then been collected. It consists of 7 databases of mainly European paintings totaling 174.012 images, of which one is contemporary art, and 3 databases of photographs totaling 25.801 images. As an example, the Cfga (2014) online art museum has 7348 images of paintings, of which Picasso has made 28 (including portraits of himself). This database is analyzed with regards to width and height primarily.

\subsection{Width and Height}

The widths and heights of the images of paintings in the Cfga database are shown in Fig. 1. Each dot on the image represents one digitalized painting. It is clear that the photographer has chosen to use some widths and heights more often than other. In particular the multiples of 50 above $600(600,650, \ldots$ 1100) are more prominent than others. In addition to this, less paintings are found in the diagonal going from $(0,0)$ to (1200, 1200), representing the square paintings. In opposition to this, there seem to be more painting to the left and right of the square diagonal.

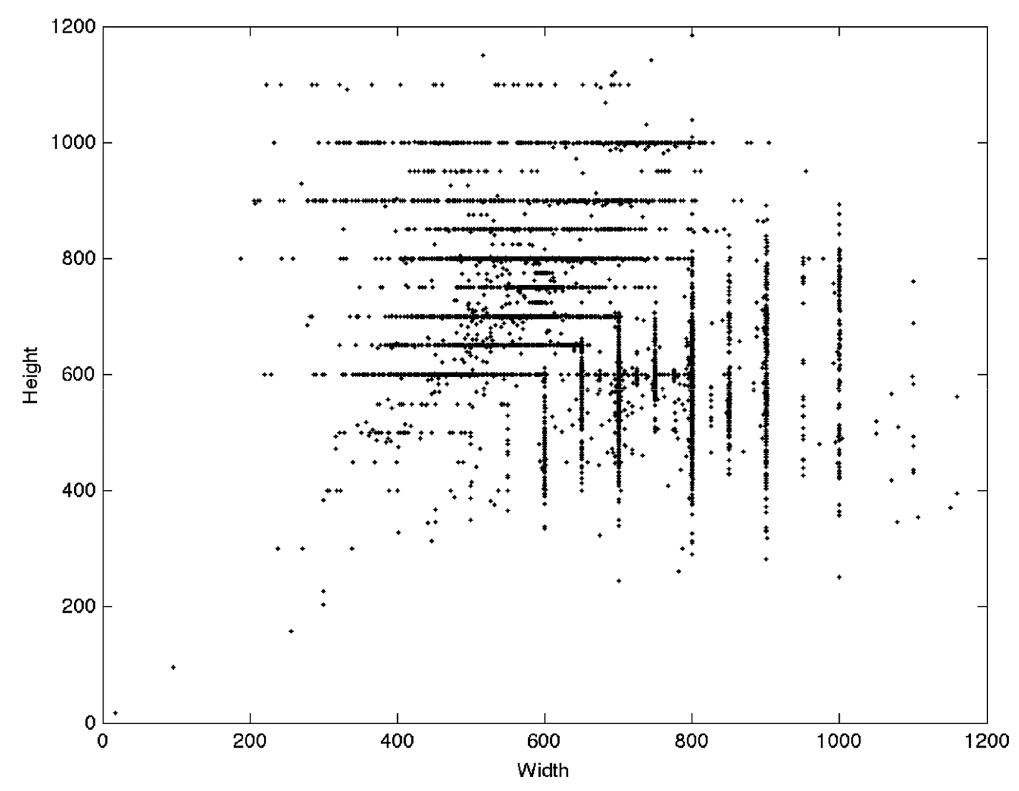

Fig. 1. Width and height of the Cfga database.

\subsection{Width/Height}

These rectangular proportions of the Cfga database can be seen in the histogram of width/ height proportions in Fig. 2. As can be expected, a wide variety of proportions are found in this database. The proportions are found from very high $(\mathrm{w} / \mathrm{h}=0.25)$ to very wide $(\mathrm{w} / \mathrm{h}=4)$ paintings. A small peak is found for the rectangular paintings, and larger peaks are found on both sides of the square position $(\mathrm{w} / \mathrm{h}=1)$. These peaks are found at position 
0.78 and 1.24 . The golden ratio positions (1.61 and 0.61$)$ are found on the descending slopes. Golden ratio $(0.61)$ has $0.30 \%$ of the maximum below square, and (1.61) has $0.20 \%$ of maximum above square. It is clear that if there exist a preference, it is not found in the vicinity of the golden ratio. The squares with proportions around one in Fig. 2 in are in part consisting of round paintings that have been photographed into a square.

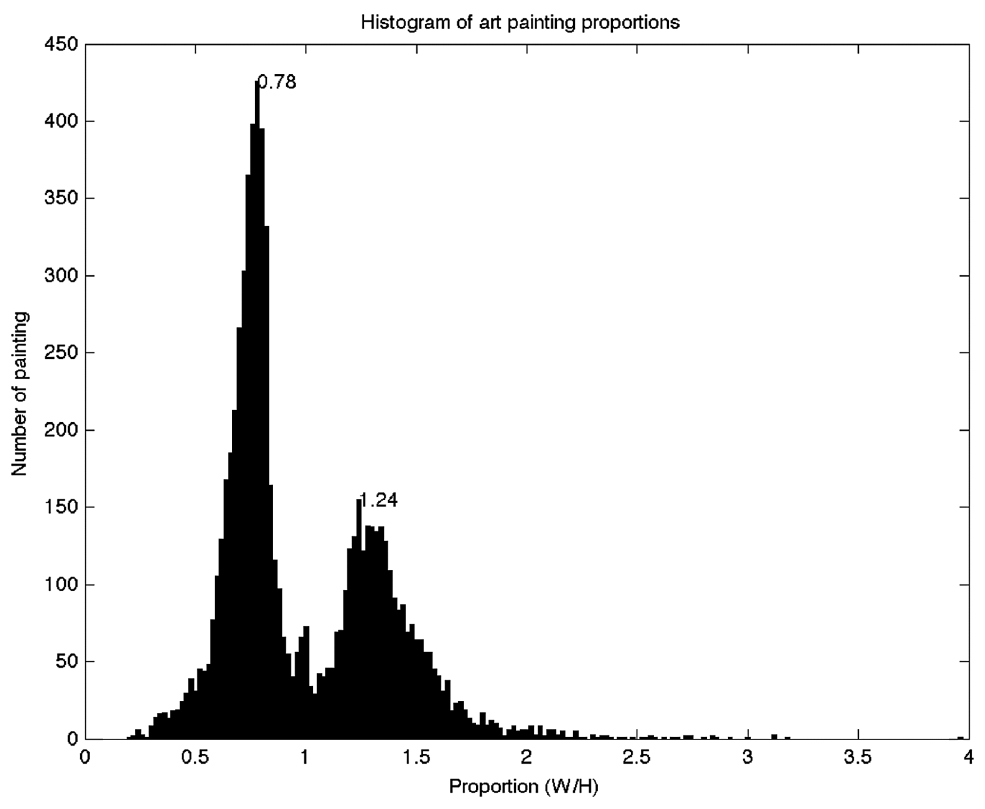

Fig. 2. Histogram of height/width proportions for the Cfga database.

The number of 'portrait' painting is larger than the number of 'landscape' paintings. This ratio is approximately 1.5 , i.e. there are $50 \%$ more portrait than landscape paintings in the Cfga database.

\subsection{Width/Height and Size}

Now, the correlation between proportions and size is investigated. The width/height proportion is plotted versus the size in Fig. 3. The discrete multiples-of-50 height and width values are prominent. The size (diagonal) is measured in pixels, as the real size metadata was not always available. No trends with regards to proportion/size relationships are present. The lines in the figure indicate that as either the width or the height increases the other dimension is constant. There is no proof or indications that the size influences the width/height proportions. 


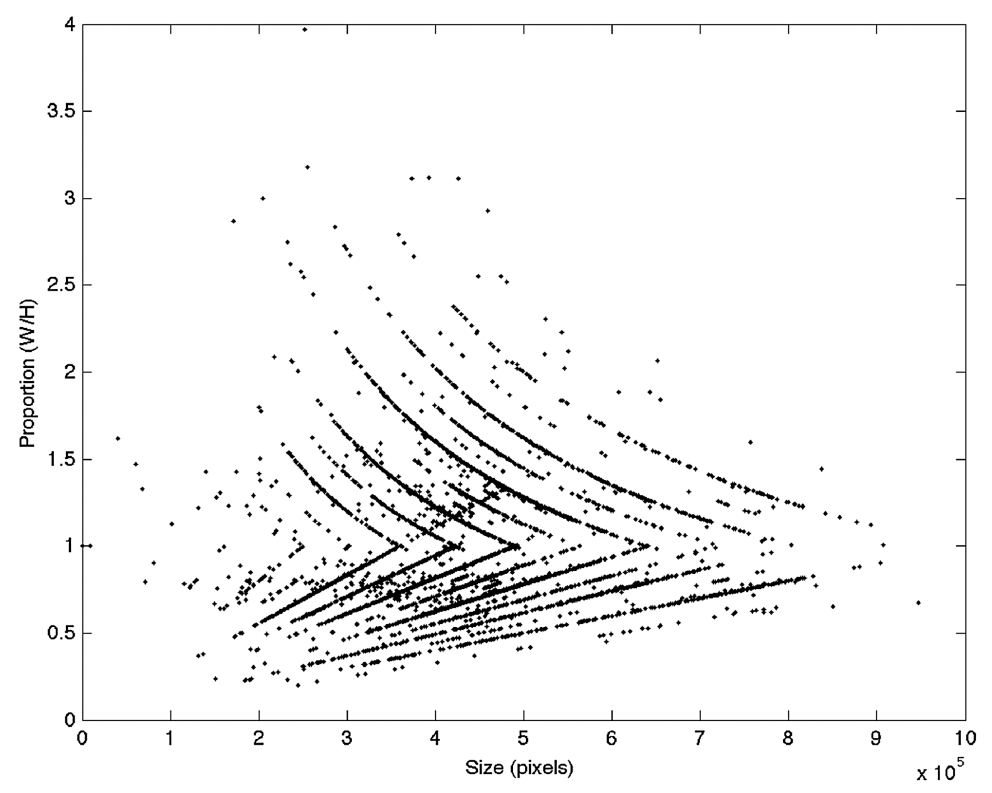

Fig. 3. Size vs width/height proportions for the Cfga database.

\subsection{Other Databases}

The Cfga database clearly demonstrates that many width/height relationships exist, preponderantly not so close to the golden ratio, and with approximately the same number of portrait and landscape proportions. In order to verify the results, the same analysis is now made using nine other databases. The results are shown in Fig. 4 for all 10 databases and the total database at the position \#11 with the maximum of the width/height histogram (left) and the golden ratio to maximum ratio (right). The maximum (left) corresponds to the two numbers written in Fig. 2 and the ratios (right) correspond to the values at the golden ratio ( 0.61 and 1.61$)$ divided by the two peak values.

It is clear from the figure that all of the databases have the maximum of the height/ width proportions around 0.8 and 1.3. The photograph databases (\# 3,8 and 9) corresponds well with these numbers. The mean of all databases are (0.77 and 1.34). This is different from the total database (\#11) as this is strongly influenced by the large photography database. The photographs and the Japanese art collection (\#7) have discrete width/height values, and so the golden ratio value does not occur at all. The portrait to landscape ratio for all databases is 1.46 , i.e. very similar to the Cfga portrait/landscape ratio.

The photographic collections height/width histogram is shown in Fig. 5.

Several discrete peaks are shown in the figure. The main ones correspond to uncropped 3/2 aspect ratio cameras, while some of the histogram discrete peaks can be linked to other uncropped aspect ratios (1/1,5/4, and 4/3 mainly). If these uncropped photos are removed from the database, the photographs also adhere approximately to 

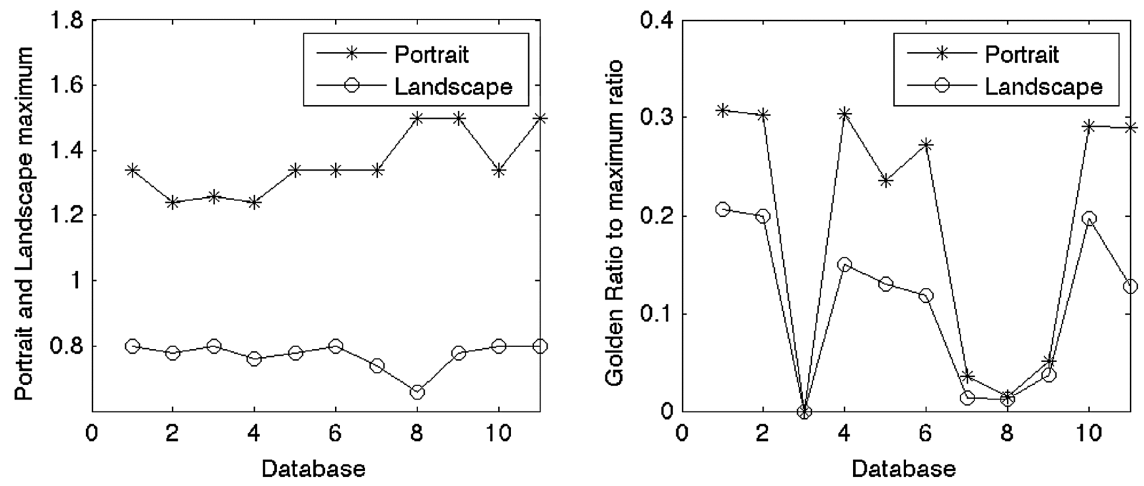

Fig. 4. Maximum of height/width histogram (left) and golden ratio to maximum ratio (right) for 11 databases.

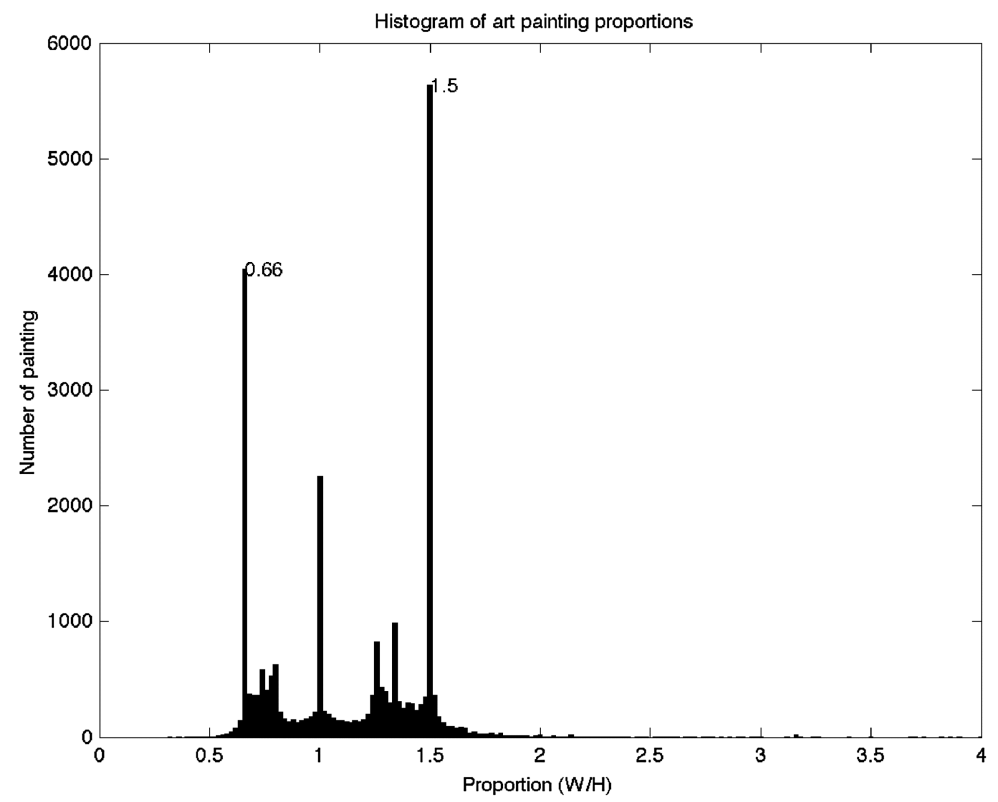

Fig. 5. Histogram of the height/width proportions for the photographic collections.

the 0.8 and 1.3 proportions. The portrait to landscape ratio is very different for the photographs, as can be seen in Fig. 5. This ratio is 0.64 , thus there are $56 \%$ more landscape than portrait photographs in these databases. 


\section{Conclusions}

Is there pure mathematics behind art, is it related to perceptual illusions, or other preferential behaviors, or are practical matters explaining art proportions. This study investigates these matters through a large-scale study of painting and photographs.

The first conclusion from this study is that the golden ratio (1.61) does not seem to be relevant, none withstanding the large number of publications that seem to indicate otherwise. All paintings are found to have mainly rectangular proportions with approximately $50 \%$ more portrait than landscape images. In the case of the photographs, there are around $56 \%$ more landscape than portrait images.

The most common proportions are found to be around 0.8 and 1.25 , which is less rectangular than modern time media (1.41 for A4 paper format, 1.78 for 16/9 HDTV). The photographs are found to be in large part uncropped, and having the proportions of the aspect ratio of the camera, most often $3 / 2$, sometimes $1 / 1$ or $5 / 4$.

The present findings are also is in opposition to the early findings of Fechner (1876) and Lalo (1908), that found preferences though analysis of book proportions closer to the golden ratio.

As a final word, with regards to proportions, anything goes, as long as it is rectangular with the width to height ratio within the limits of 0.25 to almost 1 , or the inverse in the case of landscape images. However, if you want to adhere to the most popular choice, this is found at approximately 0.8 .

\section{References}

Posamentier, A.S., Lehmann, I.: The Fabulous Fibonacci Numbers. Prometheus Books, New York (2007)

Gardner, M.: Fads and Fallacies in the Name of Science. Dover Publications Inc, New York (1952)

Green, C.D.: All that glitters: a review of psychological research on the aesthetics of the golden section. Perception 24, 937-968 (1995)

Plug, C.: The golden section hypothesis. Am. J. Psychol. 93(3), 467-487 (1980)

Elam, K.: Geometry of Design - Studies in Proportion and Composition. Princeton Architectural Press, New York (2001)

Boselie, F.: The Aesthetic Attractivity of the Golden Section. Psychol. Res. 45(4), 367-375 (2004)

Kuhn, M.: International standard paper sizes (2014). http://www.cl.cam.ac.uk/ mgk25/isopaper.html. accessed 28 February

Cfga. Online Art Museum (2014). http://www.cgfaonlineartmuseum.com/. accessed 28 February

Fechner, G.T.: Vorschule der aesthetik, Bind 1-2. Breitkopf \& Härtel (1876)

Lalo, C.: L'esthétique expérimentale contemporaine. Felix Alcan, Paris (1908)

Markowsky, G.: Misconceptions about the golden ratio. Coll. Math. J. 23(1), 2-19 (1992) 